\title{
Hypervalent iodine/TEMPO-mediated oxidation in flow systems: a fast and efficient protocol for alcohol oxidation
}

\author{
Nida Ambreen, Ravi Kumar and Thomas Wirth*
}

\author{
Full Research Paper

\section{Address:} \\ Cardiff University, School of Chemistry, Park Place, Cardiff CF10 \\ 3AT, UK

\section{Email:} \\ Thomas Wirth* - wirth@cf.ac.uk \\ * Corresponding author \\ Keywords: \\ alcohols; carbonyl compounds; flow chemistry; microreactor; oxidation
}

Open Access

\author{
Beilstein J. Org. Chem. 2013, 9, 1437-1442. \\ doi:10.3762/bjoc.9.162 \\ Received: 17 May 2013 \\ Accepted: 28 June 2013 \\ Published: 17 July 2013 \\ This article is part of the Thematic Series "Chemistry in flow systems III". \\ Guest Editor: A. Kirschning \\ () 2013 Ambreen et al; licensee Beilstein-Institut. \\ License and terms: see end of document.
}

\begin{abstract}
Hypervalent iodine(III)/TEMPO-mediated oxidation of various aliphatic, aromatic and allylic alcohols to their corresponding carbonyl compounds was successfully achieved by using microreactor technology. This method can be used as an alternative for the oxidation of various alcohols achieving excellent yields and selectivities in significantly shortened reaction times.
\end{abstract}

\section{Introduction}

Oxidation of alcohols to carbonyl compounds plays an important role in organic chemistry. The transformation is traditionally achieved by using chromium-based reagents such as the Collins reagent, activated manganese dioxide, or procedures known as the Swern [1], Pfitzner-Moffatt [2] or Parikh-Doering oxidation [3]. In synthetic chemistry, selective methods for the oxidation of alcohols are highly sought after, and methods with the ability to differentiate between various functional groups are desired. The use of hypervalent iodine reagents in organic chemistry has increased during recent years [4-6]. Hypervalent iodine compounds in general have emerged as versatile oxidizing agents with compounds such as DMP (Dess-Martin periodinane) and IBX finding regular utility as highly selective oxidizing agents [7-9]. The use of the nitroxyl radical TEMPO (2,2,6,6-tetramethylpiperidine-1-oxyl) as a catalyst in the oxidation of alcohols has gained much attention in recent years [10-12]. The redox cycle involves beside TEMPO also the corresponding hydroxylamine and the oxoammonium cation, which oxidizes the alcohol and is converted to TEMPO-H [13]. Hypervalent iodine(III) reagents in combination with a catalytic amount of TEMPO have already been reported in highly selective oxidations of alcohols to carbonyl compounds [14].

The development of efficient flow-reactor systems for molecular transformations is an important area in organic synthesis. The introduction of more general platforms to perform reactions under continuous flow rather than in batch mode has 
led to improvements regarding safety and sustainability. Microreactor technology can be beneficial over classical approaches in a variety of chemical reactions. Many reactions can benefit from the properties of microreactors. Enhanced mass- and heat transfer and short diffusion distances can lead to better yields within shorter reaction times [15]. Herein, we describe the development of continuous-flow systems using hypervalent iodine reagents in the TEMPO-mediated oxidation of alcohols with the advantage of significantly shortened reaction times. Several other oxidative processes have already been reported in flow chemistry [16].

\section{Results and Discussion}

Benzyl alcohol was chosen as a substrate in order to examine the efficiency of the reaction and the microreactor flow system. In a batch reaction, the mixture of benzyl alcohol (1a) and (diacetoxyiodo)benzene (2) did not show any reaction after stirring for $12 \mathrm{~h}$ in dichloromethane at $35^{\circ} \mathrm{C}$. The addition of a catalytic amount TEMPO to the reaction mixture led to a rapid conversion to benzaldehyde (3a). For initial investigations of a flow system, a simple setup consisting of two syringes driven by a syringe pump, a T-connector and a tubing reactor (PTFE tubing, length: $4 \mathrm{~m}$, internal diameter: $0.75 \mathrm{~mm}$ ) was used for the oxidation of benzyl alcohol to benzaldehyde. The tubing reactor was inserted in a water bath at constant temperature as shown in Figure 1. In all flow experiments, the alcohol substrate $\mathbf{1}$ and oxidant $\mathbf{2}$ were mixed in one syringe, and the reac- tion started by combining this mixture with the solvent stream of a second syringe containing the catalyst TEMPO.

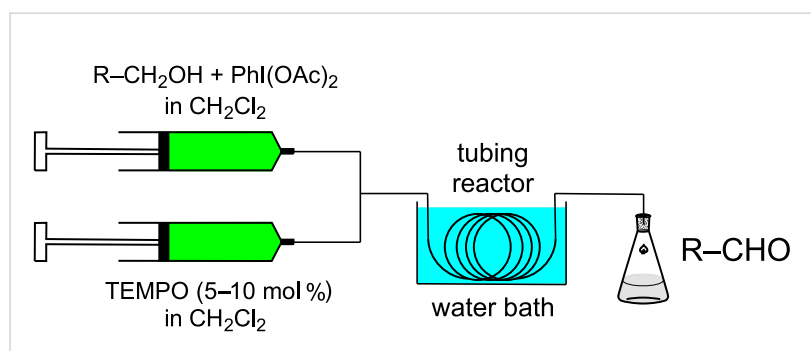

Figure 1: Flow setup for alcohol oxidations.

The reactions have been performed at $35{ }^{\circ} \mathrm{C}$. With a residence time of $30 \mathrm{~s}$ the conversion to benzaldehyde was determined by $\mathrm{GC}$ to be $52 \%$. Increasing the residence time to $1 \mathrm{~min}, 2 \mathrm{~min}$ and $4.5 \mathrm{~min}$ led to conversions of $65 \%, 79 \%$ and $95 \%$, respectively. The reaction is incomplete if performed with amounts below $5 \mathrm{~mol} \%$ of TEMPO ( $1 \mathrm{~mol} \%$ TEMPO: $67 \%$ conversion, 2 mol \% TEMPO: $81 \%$ conversion). Therefore all experiments were performed with at least $5 \mathrm{~mol} \%$ TEMPO catalyst.

To extend the substrate scope, various benzylic, aliphatic and allylic alcohols were investigated. Good yields at short reaction times and a high selectivity towards the oxidized products were observed as shown in Table 1. Over-oxidation to the corres-

Table 1: Products and yields in the oxidation of alcohols performed in a tubing reactor at a total flow rate of $0.4 \mathrm{~mL} / \mathrm{min}$ (residence time: $4.5 \mathrm{~min}$ ) at $35^{\circ} \mathrm{C}$.

Entry


Table 1: Products and yields in the oxidation of alcohols performed in a tubing reactor at a total flow rate of $0.4 \mathrm{~mL} / \mathrm{min}$ (residence time: $4.5 \mathrm{~min}$ ) at $35^{\circ} \mathrm{C}$. (continued)

6<smiles>Cc1cc([N+](=O)[O-])c(CO)c([N+](=O)[O-])c1</smiles>

7

8<smiles>OCc1ccco1</smiles><smiles>O=Cc1ccc(CO)o1</smiles>

9<smiles>CC(C)=CCC/C(C)=C/CO</smiles>

10

11

12

13

14

15

16

17

18

19

20

21

22

23
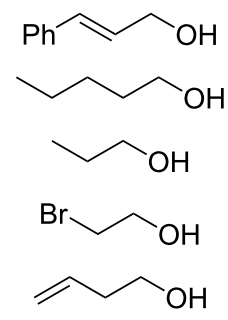<smiles>C#CCCO</smiles><smiles>C=CCCCO</smiles><smiles>CCC=C=CO</smiles><smiles>OCCCCCO</smiles><smiles>CC(O)C(C)O</smiles>

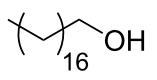<smiles>CC(O)c1ccccc1Br</smiles><smiles>O=C(O)NC(CO)Cc1ccccc1</smiles><smiles>Cc1cc(C)c(C=O)c([N+](=O)[O-])c1</smiles><smiles>O=Cc1ccc(C=O)o1</smiles>

89<smiles>CC(C)=CCC/C(C)=C/C=O</smiles>
95

n.d.

52

[33]

$96 \quad 76$

$\begin{array}{ll}97 & 97\end{array}$

$\begin{array}{ll}89 & 87\end{array}$

100

56

87

100

87

88

91

77<smiles>CC(=O)c1ccccc1Br</smiles><smiles>O=CC(Cc1ccccc1)N[18O]C(=O)O</smiles>

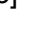
$\mathrm{Ph}_{\mathrm{O}}$ NHBoc

40 ponding carboxylic acids was not detected and high selectivities were obtained.

In larger scale reactions $(0.5 \mathrm{~g})$, the conversion monitored by GC was nearly quantitative. Isolated yields were lower than those indicated by GC and largely reflect losses from isolation procedures for individual products. The optimized reaction time of 4.5 min was then used to convert also a larger amount of benzyl alcohol (15 mmol) to benzaldehyde, which was isolated as the reaction product in $49 \%$ yield. These results provide further evidence that this flow process is effective for oxidation methods initially discovered and developed under batch conditions. The substrate scope of the catalytic method in this flow process reflects that of the method originally developed in 
batch. $N$-Boc protected $(S)$-phenylalaninol [34] (Table 1, entry 22) was oxidized to the corresponding aldehyde [35] without loss of optical purity as determined by the optical rotations of starting material and product [36]. $N$-Boc protected (S)phenylglycinol [37] (Table 1, entry 23) suffered from some optical degradation probably during the work-up [38]. Aldehydes are rarely target molecules of pharmaceutical synthesis. These functional groups rather represent highly useful intermediates for subsequent reactions. The addition of 1,2diaminobenzene to the crude oxidation product of 2,3-butanediol (Table 1, entry 19) allowed the direct and almost quantitative synthesis of 2,3-dimethylquinoxaline with para-toluenesulfonic acid as catalyst in the subsequent condensation reaction performed in a batch system (Scheme 1) [39] The oxidation-condensation sequence described here generates almost no byproducts except iodobenzene which can be removed very easily during the chromatographic purification of the product and should enable direct progression to the subsequent synthetic steps, without the need for isolation or purification of the intermediate aldehyde or ketone.

\section{Conclusion}

In conclusion, a highly efficient and selective continuous-flow reaction for the oxidation of different alcohols was developed. Apart from short reaction times, high conversions and excellent selectivities were obtained. These features, together with the low toxicity of the reagents, make the process attractive compared to the batch reaction. The economical and benign oxidation is broadly applicable to a wide range of alcohols.

\section{Experimental}

General: ${ }^{1} \mathrm{H}$ NMR and ${ }^{13} \mathrm{C}$ NMR spectra were recorded on a AV-400 Bruker spectrometer by using the solvents indicated with 400 and $100 \mathrm{MHz}$, respectively. All reactions were monitored by thin-layer chromatography that was performed on precoated sheets of silica gel 60. GC analyses were performed on a GC-FID (Varian 3900) chromatograph. All purchased chemicals were used without further purification.

\section{General procedure for the alcohol oxidation in flow}

Solutions of (diacetoxyiodo)benzene (1.1 equiv) and the alcohol (50 mg) in $\mathrm{CH}_{2} \mathrm{Cl}_{2}(1.5 \mathrm{~mL})$ and 2,2,6,6-tetramethyl-1piperidinyloxyl (TEMPO) (5-10 mg, 10-20 mol \%) in $\mathrm{CH}_{2} \mathrm{Cl}_{2}$ $(1.5 \mathrm{~mL})$ were loaded in two syringes. Both syringes were placed in a syringe pump (Fusion 100) and connected via a T-piece to a tubing reactor (PTFE, length: $4 \mathrm{~m}$, internal diameter: $0.75 \mathrm{~mm}$ ). The tubing reactor was immersed in a thermocontrolled water bath at $35{ }^{\circ} \mathrm{C}$. The total flow rate was adjusted to $0.4 \mathrm{~mL} \mathrm{~min}{ }^{-1}$ resulting in a residence time of $4.5 \mathrm{~min}$. The reaction mixture exiting the flow reactor was quenched with water and, after completion of the reaction, extracted with $\mathrm{CH}_{2} \mathrm{Cl}_{2}$. The combined organic layers were dried over magnesium sulfate and the solvents were removed in vacuo. Direct analysis with GC allowed the determination of the conversion by comparison of the product peak with the peak of the starting alcohol.

\section{Large scale oxidation of benzyl alcohol in flow}

The reaction was performed with the Vapourtec E-Series using a PFA tubing reactor. Benzyl alcohol (2 g, $18.5 \mathrm{mmol})$ and (diacetoxyiodo)benzene $(6.3 \mathrm{~g} 19.5 \mathrm{mmol})$ were dissolved in $\mathrm{CH}_{2} \mathrm{Cl}_{2}$ (120 mL). 2,2,6,6-Tetramethyl-1-piperidinyloxyl (TEMPO) (160 mg, $1 \mathrm{mmol}$ ) was dissolved in $\mathrm{CH}_{2} \mathrm{Cl}_{2}$ $(120 \mathrm{~mL})$. Both solutions (flow rates: $2 \mathrm{~mL} \mathrm{~min}^{-1}$ each) were mixed in a $\mathrm{T}$-piece before entering the tubing reactor (volume: $10 \mathrm{~mL}$ ) resulting in a residence time of $5 \mathrm{~min}$. After constant flow had been achieved, $200 \mathrm{~mL}$ of the reaction solution was collected in a flask containing water $(20 \mathrm{~mL})$ as a quenching agent. After completion of the reaction, the organic phase was removed and the aqueous phase was extracted with $\mathrm{CH}_{2} \mathrm{Cl}_{2}$ $(3 \times 20 \mathrm{~mL})$. The combined organic layers were dried over magnesium sulfate, and the solvents were removed in vacuo. The crude reaction mixture was purified by flash chromatography on silica using hexane/ethyl acetate (9:1) as eluent. Some benzaldehyde was lost during the drying processes and $0.8 \mathrm{~g}$ ( $7.5 \mathrm{mmol}, 49 \%)$ was isolated.

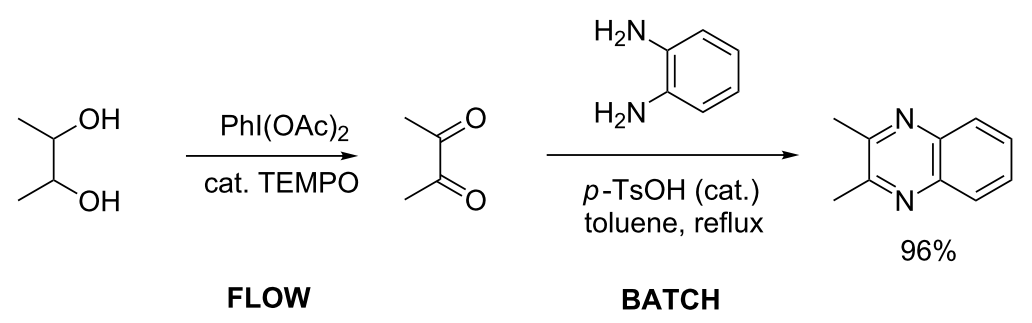




\section{Procedure for the aldehyde and diamine con- densation}

1,2-Phenylenediamine $(0.59 \mathrm{mg} 0.55 \mathrm{mmol})$ was added to the crude oxidized product of 2,3-butanediol (50 $\mathrm{mg} 0.55 \mathrm{mmol}$ ) and dissolved in toluene in a round-bottom flask, and $p$-toluenesulfonic acid was added as catalyst. The reaction mixture was heated under reflux for 2 hours and monitored by TLC. After the completion of the reaction the solvent was evaporated, and the reaction mixture was extracted with $\mathrm{CH}_{2} \mathrm{Cl}_{2}$ and water. The organic layers were dried over magnesium sulfate and the solvents were removed in vacuo. The ${ }^{1} \mathrm{H}$ NMR analysis showed a clean spectrum of the condensation product.

\section{Acknowledgements}

We thank the Schlumberger Foundation for support through a Faculty for the Future fellowship (N.A.) and the EPSRC National Mass Spectrometry Facility, Swansea, for mass spectrometric data.

\section{References}

1. Omura, K.; Swern, D. Tetrahedron 1978, 34, 1651-1660. doi:10.1016/0040-4020(78)80197-5

2. Pfitzner, K. E.; Moffatt, J. G. J. Am. Chem. Soc. 1963, 85, 3027-3028. doi:10.1021/ja00902a036

3. Parikh, J. R.; Doering, W. v. E. J. Am. Chem. Soc. 1967, 89, 5505-5507. doi:10.1021/ja00997a067

4. Hypervalent lodine Chemistry. In Modern Developments in Organic Synthesis; Wirth, T., Ed.; Topics in Current Chemistry; 2003; p 224.

5. Zhdankin, V. V. ARKIVOC 2009, (i), 1-62.

6. Wirth, T. Angew. Chem., Int. Ed. 2005, 44, 3656-3665. doi:10.1002/anie.200500115

7. Wirth, T. IBX - New Reactions with an Old Reagent. In Organic Synthesis Highlights V; Schmalz, H.-G.; Wirth, T., Eds.; Wiley-VCH: Weinheim, Germany, 2003; pp 144-150.

8. Richardson, R. D.; Zayed, J. M.; Altermann, S.; Smith, D.; Wirth, T. Angew. Chem., Int. Ed. 2007, 46, 6529-6532. doi:10.1002/anie.200702313

9. Tohma, H.; Kita, Y. Adv. Synth. Catal. 2004, 346, 111-124. doi:10.1002/adsc.200303203

10. Bobbit, J. M.; Brückner, C.; Merbouh, N. Org. React. 2009, 74, 106-424. doi:10.1002/0471264180.or074.02

11. Tebben, L.; Studer, A. Angew. Chem., Int. Ed. 2011, 50, 5034-5068. doi:10.1002/anie.201002547

12. Tilley, L. J.; Bobbitt, J. M.; Murray, S. A.; Camire, C. E.; Eddy, N. A Synthesis 2013, 45, 326-329. doi:10.1055/s-0032-1317861

13. Ma, Y.; Loyns, C.; Price, P.; Chechik, V. Org. Biomol. Chem. 2011, 9 , 5573-5578. doi:10.1039/c1ob05475a

14. De Mico, A.; Margarita, R.; Parlanti, L.; Vescovi, A.; Piancatelli, G. J. Org. Chem. 1997, 62, 6974-6977. doi:10.1021/jo971046m

15. Wirth, T., Ed. Microreactors in Organic Synthesis and Catalysis; Wiley-VCH: Weinheim, Germany, 2013.

16. Ye, X.; Johnson, M. D.; Diao, T.; Yates, M. H.; Stahl, S. S. Green Chem. 2010, 12, 1180-1186. doi:10.1039/c0gc00106f

17. linuma, N.; Moriyama, K.; Togo, H. Tetrahedron 2013, 69, 2961-2970. doi:10.1016/j.tet.2013.02.017
18. Lin, C.-K.; Lu, T.-J. Tetrahedron 2010, 66, 9688-9693. doi:10.1016/j.tet.2010.10.053

19. Hoover, J. M.; Stahl, S. S. J. Am. Chem. Soc. 2011, 133, 16901-16910. doi:10.1021/ja206230h

20. Claramunt, R. M.; López, C.; López, A.; Pérez-Medina, C. Pérez-Torralba, M.; Alkorta, I.; Elguero, J.; Escames, G.; Acuña-Castroviejo, D. Eur. J. Med. Chem. 2011, 46, 1439-1447. doi:10.1016/j.ejmech.2011.01.027

21. Hu, Y. L.; Liu, Q. F.; Lu, T. T.; Lu, M. Catal. Commun. 2010, 11, 923-927. doi:10.1016/j.catcom.2010.03.017

22. Hanson, S. K.; Wu, R.; Silks, L. A. Org. Lett. 2011, 13, 1908-1911. doi:10.1021/ol103107v

23. The Aldrich Library of ${ }^{13} \mathrm{C}$ and ${ }^{1} \mathrm{H}$ FT NMR Spectra, Alrich Chemical Company Inc., 1993, Vol. 1, 729C.

24. Makulski, W.; Jackowski, K. J. Mol. Struct. 2003, 651-653, 265-269. doi:10.1016/S0022-2860(02)00638-5

25. Li, W.; Li, J.; Wu, Y.; Fuller, N.; Markus, M. A. J. Org. Chem. 2010, 75, 1077-1086. doi:10.1021/jo902014z

26. Airiau, E.; Spangenberg, T.; Girard, N.; Breit, B.; Mann, A. Org. Lett. 2010, 12, 528-531. doi:10.1021/ol902718q

27. Blankespoor, R. L.; Smart, R. P.; Batts, E. D.; Kiste, A. A.; Lew, R. E.; Van Vliet, M. E. J. Org. Chem. 1995, 60, 6852-6859. doi:10.1021/jo00126a040

28. Siebuma, A.; van Wijk, A.; Schoevaart, R.; Kieboom, T. J. Mol. Catal. B 2006, 41, 141-145. doi:10.1016/j.molcatb.2006.04.003

29. Hardy, P. M.; Nicholls, A. C.; Rydon, H. N. J. Chem. Soc., Perkin Trans. 2 1972, 2270-2278. doi:10.1039/P29720002270

30. Hirasawa, S.; Watanabe, H.; Kizuka, T.; Nakagawa, Y.; Tomishige, K. J. Catal. 2013, 300, 205-216. doi:10.1016/j.jcat.2013.01.014

31. Biraboneye, A. C.; Madonna, S.; Maher, P.; Kraus, J.-L. ChemMedChem 2010, 5, 79-85. doi:10.1002/cmdc.200900418

32. Schröder, N.; Wencel-Delord, J.; Glorius, F. J. Am. Chem. Soc. 2012, 134, 8298-8301. doi:10.1021/ja302631j

33. Morita, T.; Nagasawa, Y.; Yahiro, S.; Matsunaga, H.; Kunieda, T. Org. Lett. 2001, 3, 897-899. doi:10.1021/ol015535r

34. Wu, Y.-C.; Zhu, J. J. Org. Chem. 2008, 73, 9522-9524. doi:10.1021/j08021988

35. Alfaro, R.; Yuste, F.; Ortiz, B.; Sánchez-Obregón, R.; Ruano, J. L. G. Tetrahedron 2009, 65, 357-363. doi:10.1016/j.tet.2008.10.037

36. (S)- $N$-(tert-Butyloxycarbonyl)phenylalaninol: $[\alpha]_{D}{ }^{27}=-24.0(c=0.83$, $\left.\mathrm{CHCl}_{3}\right)$; literature [34]: $[\alpha]_{D}{ }^{25}=-27.0\left(c=1.7, \mathrm{CHCl}_{3}\right.$

$(S)-N$-(tert-Butoxycarbonyl)-2-amino-3-phenylpropanal: $[\alpha]_{D}{ }^{25}=-36.0$ $(c=0.5, \mathrm{MeOH})$; literature $[35][\alpha]_{D}=-37.9(c=1.0, \mathrm{MeOH})$.

37. Cox, G. G.; Harwood, L. M. Tetrahedron: Asymmetry 1994, 5 , 1669-1672. doi:10.1016/0957-4166(94)80077-4

38. (S)- $N$-(tert-Butyloxycarbonyl)phenylglycinol: $[\alpha]_{D}{ }^{27}=+37.0(c=0.97$, $\left.\mathrm{CHCl}_{3}\right)$; literature [37]: $[\alpha]_{D}{ }^{23}=+38.7\left(c=1.06, \mathrm{CHCl}_{3}\right)$.

$(S)-N$-(tert-Butoxycarbonyl)-2-amino-2-phenylethanal: $[\alpha]_{D}{ }^{25}=-0.5(c$ $=0.06, \mathrm{MeOH})$; literature $[33][\alpha]_{\mathrm{D}}=-2.9\left(c=3.0, \mathrm{CHCl}_{3}\right)$.

39. Morales-Castellanos, J. J.; Ramirez-Hernández, K.; Gómez-Flores, N. S.; Rodas-Suárez, O. R.; Peralta-Cruz, J. Molecules 2012, 17, 5164-5176. doi:10.3390/molecules 17055164 


\section{License and Terms}

This is an Open Access article under the terms of the Creative Commons Attribution License

(http://creativecommons.org/licenses/by/2.0), which permits unrestricted use, distribution, and reproduction in any medium, provided the original work is properly cited.

The license is subject to the Beilstein Journal of Organic Chemistry terms and conditions:

(http://www.beilstein-journals.org/bjoc)

The definitive version of this article is the electronic one which can be found at:

doi:10.3762/bjoc. 9.162 